\title{
Tuberculose pulmonar: achados na tomografia computadorizada de alta resolução do tórax em pacientes com doença em atividade comprovada bacteriologicamente"
}

\author{
Cristiane Aló CAmpos ${ }^{1}$, Edson MARCHIORI ${ }^{2}$, ROSANA ROdRIGUES $^{3}$
}

\begin{abstract}
Objetivo: Descrever os achados em pacientes com tuberculose pulmonar em atividade na tomografia computadorizada de alta resolução e o padrão de distribuição das lesões pelo parênquima pulmonar.

Casuística e método: Foram analisadas retrospectivamente as tomografias de alta resolução de 42 pacientes com diagnóstico bacteriológico de tuberculose pulmonar ou forte suspeita clínica, com posterior confirmação bacteriológica. Resultados: Os principais sinais sugestivos de atividade encontrados foram nódulos do espaço aéreo (83\%), nódulos centrolobulares (74\%), aspecto de árvore em brotamento (67\%), cavitações (67\%), espessamento das paredes brônquicas (55\%), consolidações $(48 \%)$, opacidade em vidro fosco (21\%), e espessamento do interstício pulmonar (9\%). Conclusão: A tomografia computadorizada de alta resolução do tórax pode sugerir fortemente atividade da doença,

sendo particularmente útil nos pacientes com baciloscopias negativas e/ou radiografias

indeterminadas, permitindo a instituição de tratamento adequado, antes mesmo do crescimento da micobactéria em meio de cultura. (J Pneumol 2002;28(1):23-9)
\end{abstract}

\section{Pulmonary tuberculosis: findings on high resolution computerized tomography of active disease on patients with bacteriological confirmation}

Background: The aim of this study was to describe the signs of active tuberculosis in patients submitted to high resolution computerized tomography and the distribution of lesions along the pulmonary parenchyma. Material and methods: The high resolution CTs performed on 42 patients with tuberculosis either bacteriologically diagnosed or clinical suspected and later confirmed by bacteriological tests were studied. Results: The signs of disease activity observed were airspace nodule $(83 \%)$, centrilobular nodule $(74 \%)$, tree-in-bud pattern $(67 \%)$, cavitations (67\%), bronchial thickening (55\%), parenchymal consolidations $(48 \%)$, ground glass opacity (21\%) and thickening of the inter and intralobular septa (9\%). Conclusion: High resolution computed tomography can be strongly suggestive of disease activity, is particularly helpful in patients with negative smear and/or undetermined radiographs, and allows the establishment of proper treatment, even before mycobacteria are identified in means of culture.

* Trabalho realizado no Serviço de Radiodiagnóstico do Hospital Universitário Clementino Fraga Filho (HUCFF), da Universidade Federal do Rio de Janeiro (UFRJ).

1. Mestranda em Radiologia da UFRJ.

2. Professor Titular de Radiologia da Universidade Federal Fluminense; Coordenador Adjunto do Curso de Pós-Graduação em Radiologia da UFRJ.

3. Médica do Serviço de Radiodiagnóstico do HUCFF-UFRJ.

Endereço para correspondência - Edson Marchiori, Rua Thomaz Cameron, 438 - 25685-120 - Petrópolis, RJ. Tel.: (24) 243-7013;

E-mail: edmarchiori@zipmail.com.br

Recebido para publicação em 6/7/01. Aprovado, após revisão, em 5/11/01.
Descritores - Tuberculose pulmonar. Tomografia computadorizada por raios $\mathrm{X}$.

Key words - Pulmonary tuberculosis. X-ray computed tomography.

Siglas e abreviaturas utilizadas neste trabalho HUCFF - Hospital Universitário Clementino Fraga Filho TCAR - Tomografia computadorizada de alta resolução VIH - Vírus da imunodeficiência humana 


\section{INTRODUÇÃO}

A tuberculose é uma doença infecto-contagiosa causada pelo Mycobacterium tuberculosis, que ainda é freqüente em países subdesenvolvidos, como o Brasil(1).

Nos últimos anos vem sendo descrito aumento na incidência de tuberculose em vários países, em especial nos centros urbanos e regiões de elevada prevalência de infecção pelo vírus da imunodeficiência humana (VIH). Em alguns locais, além do aumento da incidência, também ocorreu mudança importante na dinâmica da transmissão da tuberculose. Essa mudança foi mais evidente nos ambientes hospitalares, onde é elevada a prevalência de indivíduos portadores de co-morbidades, como infecção pelo VIH, câncer, diabetes, etc. Nesse grupo de pacientes a tuberculose pode ser indistinguível de outras enfermidades, determinando internações mais prolongadas e, muitas vezes, sem o adequado isolamento respiratório, ocasionando aumento na transmissão da tuberculose intrahospitalar ${ }^{(2)}$.

No mundo, existem quase dois bilhões de indivíduos infectados pelo $\mathrm{M}$. tuberculosis, a grande maioria vivendo em países subdesenvolvidos ou emergentes ${ }^{(3)}$.

O diagnóstico de atividade de doença em pacientes com tuberculose pulmonar depende de múltiplos fatores, como quadro clínico, exame físico, teste tuberculínico e, principalmente, a detecção do bacilo no escarro, no lavado broncoalveolar, em aspirado transtraqueal ou em fragmentos de tecido pulmonar obtidos por biópsia, sendo reforçado por outros fatores, como alterações seqüenciais em radiografias de tórax e história prévia de terapia antituberculosa. Contudo, em virtude de a baciloscopia de escarro poder ser negativa em 21 a $66 \%$ dos casos, a cultura do mesmo poder levar até seis semanas para o crescimento de colônias e os achados nas radiografias de tórax serem freqüentemente classificados como indeterminados, o diagnóstico de atividade pode ser difícil ${ }^{(4-6)}$.

Radiologicamente, a tuberculose pulmonar pode apresentar-se de diversas formas ${ }^{(7)}$. Apesar de a radiografia de tórax poder oferecer informações sobre a atividade da doença, algumas alterações parenquimatosas mínimas podem não ser identificadas, principalmente em estágios iniciais da doença, em que aquela pode ser normal ${ }^{(4,8)}$.

A tomografia computadorizada de alta resolução (TCAR) mostrou-se superior à radiografia simples e à tomografia convencional de tórax na avaliação da presença e extensão das alterações parenquimatosas, já que permite a localização da doença ao nível do lóbulo pulmonar secundário( ${ }^{(8-10)}$. Por isso, esse método pode, em determinadas circunstâncias, ser capaz de distinguir lesões residuais de lesões recentes, mostrar precocemente nódulos miliares e lesões centrolobulares, estas últimas caracterizando a disseminação broncogênica, avaliar a presença de peque- nas cavitações, de opacidades em vidro fosco e de espessamento dos septos interlobulares, sendo especialmente útil nos pacientes com baciloscopia negativa, já que pode determinar a instituição de antibioticoterapia antes dos resultados da cultura ${ }^{(5,8,11)}$.

Além disso, a TCAR pode ser útil no diagnóstico diferencial com outras doenças pulmonares, por vezes podendo dispensar a utilização de métodos invasivos para obtenção de materiais para avaliação histopatológica ou bacteriológica $^{(12)}$.

Os objetivos deste trabalho foram: 1) discutir a importância da TCAR no diagnóstico da tuberculose pulmonar em atividade; 2) descrever os achados tomográficos em pacientes com doença pulmonar em atividade e os padrões de distribuição da doença pelos pulmões.

\section{CASUÍSTICA E MÉTOdOS}

Foram analisadas retrospectivamente 42 tomografias realizadas no Serviço de Radiodiagnóstico do Hospital Universitário Clementino Fraga Filho (HUCFF), no período de setembro de 1998 a agosto de 2000, de pacientes oriundos dos ambulatórios do Programa de Controle da Tuberculose Hospitalar e do Posto de Saúde de Campo Grande, Rio de Janeiro.

Os critérios de inclusão foram: diagnóstico bacteriológico para tuberculose pulmonar (baciloscopia e/ou cultura positivas) ou forte suspeita clínica, com posterior confirmação bacteriológica.

Foram excluídos os pacientes que apresentavam SIDA, doenças pulmonares associadas e aqueles que haviam iniciado tratamento específico há mais de 20 dias.

As tomografias de alta resolução de tórax foram realizadas em um tomógrafo Somaton AR (Siemens), com cortes axiais de $2 \mathrm{~mm}$ de espessura e $10 \mathrm{~mm}$ de incremento, dos ápices até as bases pulmonares. Foram utilizados algoritmos de alta freqüência, matriz 512 x 512; a janela e o centro variaram de 1.000 a $1.300 \mathrm{UH}$ e -600 a -700UH, respectivamente.

Dessa forma, foram estudados os casos de 42 pacientes com diagnóstico bacteriológico e radiológico de tuberculose pulmonar. Destes, $21(50 \%)$ eram do sexo masculino e 21 (50\%), do feminino. A idade dos pacientes, na época do diagnóstico da doença, variou entre 14 e 73 anos, com média de 39 anos e mediana de 38,5 anos. Quanto à distribuição em relação às faixas etárias, cinco $(12 \%)$ estavam na $2^{\mathrm{a}}$ década, $10(24 \%)$ na $3^{\mathrm{a}}$ década, sete $(17 \%)$ na $4^{\mathrm{a}}$ década, $11(26 \%)$ na $5^{\mathrm{a}}$ década, cinco $(12 \%)$ na $6^{\mathrm{a}}$ década, três $(7 \%)$ na $7^{\mathrm{a}}$ década e um $(2 \%)$ na $8^{a}$ década de vida.

O diagnóstico de tuberculose pulmonar foi feito através de baciloscopia positiva em 32 pacientes (76\%). Dez (24\%) dos 42 pacientes apresentaram baciloscopia nega- 
tiva, seja no escarro espontâneo, escarro induzido ou no lavado broncoalveolar, e o diagnóstico só foi confirmado com o crescimento de colônias em meio de cultura adequado, após um período que variou de 21 a 60 dias.

Em relação ao quadro clínico à época do exame tomográfico, a tosse foi o sintoma mais freqüente, sendo referida por 40 pacientes (95\%). Trinta e um pacientes qualificaram a tosse como produtiva e com expectoração amarelada, e nove como seca. A febre e o emagrecimento foram outras manifestações clínicas freqüentes, sendo referidas por $67 \%$ e $55 \%$ dos pacientes, respectivamente.

A análise da TCAR incluía a avaliação exclusiva do parênquima pulmonar quanto à presença dos sinais sugestivos de atividade da doença, como opacidades centrolobulares, consolidação, opacidade em vidro fosco sem sinais de fibrose associados, cavitação, nódulos do espaço aéreo e miliares, e espessamento das paredes brônquicas e dos septos intra e interlobulares. Não foi objetivo deste estudo a avaliação de alterações mediastinais ou pleurais.

\section{Resultados}

\section{Distribuição das lesões}

Dos 42 casos estudados, 29 (69\%) apresentaram acometimento múltiplo do parênquima pulmonar, com dois ou mais lobos envolvidos. Em $10 \%$ dos pacientes, observaram-se lesões em dois lobos. O acometimento difuso, com lesões nos cinco lobos, foi encontrado em sete casos. Somente 13 pacientes (31\%) apresentaram comprometimento de apenas um lobo (Quadro 1).

Observou-se predomínio das lesões nos lobos superiores, sendo o lobo superior direito o mais envolvido (71\%). Trinta pacientes apresentaram lesões no lobo superior direito e 26 (62\%) no lobo superior esquerdo. Houve importante acometimento dos lobos inferiores $(59 \%$ à esquerda e $57 \%$ à direita), e apenas 14 pacientes (33\%) apresentaram envolvimento do lobo médio (Quadro 2). Os segmentos mais envolvidos foram os apicais e posteriores dos lobos superiores e superiores dos lobos inferiores.

\begin{tabular}{|ccc|}
\hline \multicolumn{3}{|c|}{$\begin{array}{c}\text { QUADRO 1 } \\
\text { Freqüência de acometimento dos lobos pulmonares }\end{array}$} \\
\hline $\begin{array}{c}\text { Quantidade de } \\
\text { lobos acometidos }\end{array}$ & $\begin{array}{c}\mathrm{N}^{\circ} \text { de casos } \\
(\mathrm{n}=42)\end{array}$ & Percentagem \\
\hline Um lobo & 13 & \\
Dois lobos & 4 & $31 \%$ \\
Três lobos & 9 & $10 \%$ \\
Quatro lobos & 9 & $21 \%$ \\
Cinco lobos & 7 & $21 \%$ \\
\hline
\end{tabular}

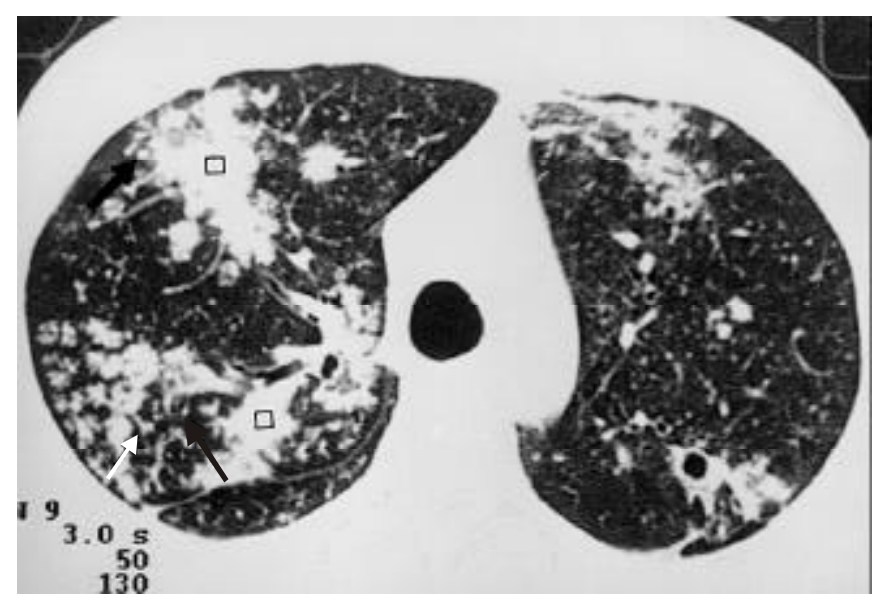

Figura 1 - TCAR. Múltiplos focos de condensação dispersos pelo parênquima pulmonar (quadrado), com nódulos do espaço aéreo (seta grossa), nódulos centrolobulares (seta fina) e preenchimento bronquiolar adjacente (seta vazada). O bserva-se também pequena cavidade no lobo superior esquerdo.

\section{Aspectos tomográficos}

Na avaliação das TCAR dos 42 pacientes, observou-se que $90 \%$ delas apresentavam pelo menos um tipo de opacidade centrolobular. Se for levado em consideração que os nódulos do espaço aéreo apresentam localização centrolobular, pode-se afirmar que $97 \%$ dos pacientes apresentaram algum tipo de opacidade centrolobular. Os nódulos do espaço aéreo predominaram e foram encontrados em 35 pacientes (83\%), seguidos dos nódulos centrolobulares em 31 (74\%) e do aspecto de árvore em brotamento em 28 (67\%) (Figura 1).

A associação entre essas lesões (Figura 2) foi freqüente, ocorrendo em $83 \%$ dos casos ( 35 pacientes). O achado de um único tipo de opacidade centrolobular ocorreu em três pacientes com nódulos do espaço aéreo, em três com nódulos centrolobulares e em um paciente com aspecto de árvore em brotação.

A cavitação também foi um achado freqüente, ocorrendo em 28 pacientes (65\%), sendo múltiplas em $53 \%$

\begin{tabular}{|c|c|c|c|}
\hline \multicolumn{4}{|c|}{$\begin{array}{c}\text { QUADRO } 2 \\
\text { Freqüência do acometimento pulmonar }\end{array}$} \\
\hline \multicolumn{2}{|c|}{ Localização } & $\begin{array}{l}N^{0} \text { de pacientes } \\
\quad(\mathrm{n}=42)\end{array}$ & Percentagem \\
\hline \multirow[t]{3}{*}{ Pulmão direito } & Lobo superior & 30 & $71 \%$ \\
\hline & Lobo médio & 14 & $33 \%$ \\
\hline & Lobo inferior & 24 & $57 \%$ \\
\hline \multirow[t]{2}{*}{ Pulmão esquerdo } & Lobo superior & 26 & $62 \%$ \\
\hline & Lobo inferior & 25 & $59 \%$ \\
\hline
\end{tabular}




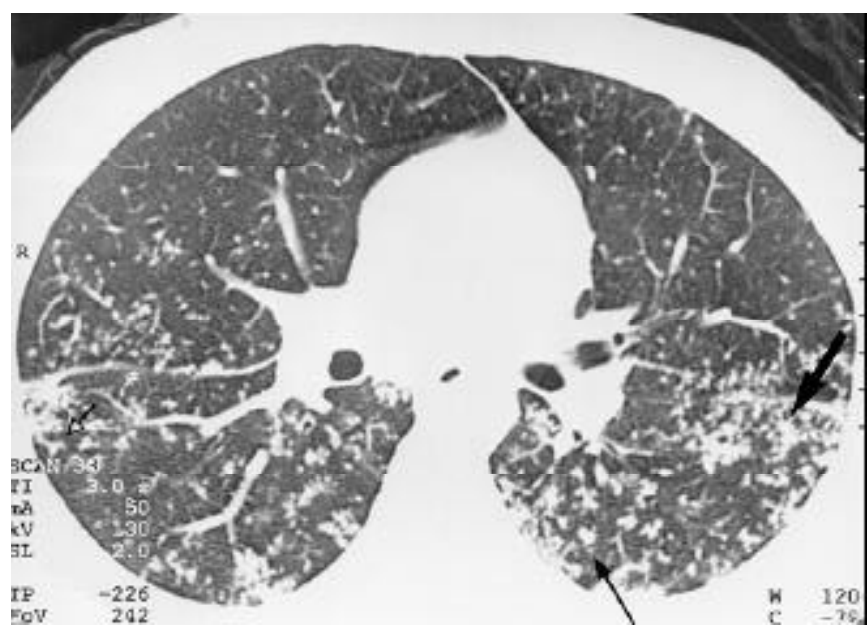

Figura 2 - TCAR. O pacidades centrolobulares ramificadas (aspecto de árvore em brotação) (seta vazada), nódulos centrolobulares (seta fina) e do espaço aéreo (seta grossa), alguns confluentes, predominando nos segmentos superiores dos lobos inferiores.

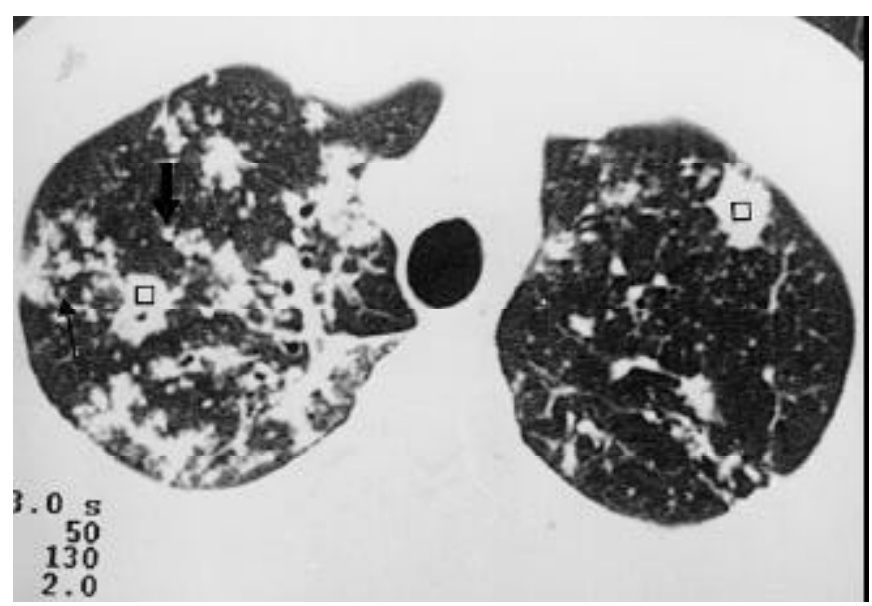

Figura 4 - TCAR. Múltiplos focos de consolidação dispersos pelo parênquima pulmonar (quadrado), com aspecto "em cachos", associados a nódulos do espaço aéreo (seta grossa), confluentes, e nódulos centrolobulares (seta fina).

dos casos. O tamanho das cavidades variou de 1,5 a $5,5 \mathrm{~cm}$. Vinte e quatro dos 28 pacientes com cavitação $(86 \%)$ apresentaram cavidades de paredes espessas e bordas irregulares (Figura 3). Três pacientes (11\%) apresentaram cavidade de paredes espessas e bordas regulares e um $(3 \%)$, cavidades de paredes finas e irregulares. A presença de nível líquido foi encontrada em apenas um paciente. Em 89\% dos casos com cavitação, foi observada associação com nódulos do espaço aéreo e opacidades centrolobulares.

Consolidações com broncograma aéreo de permeio foram observadas em $48 \%$ dos casos, sendo que, em metade dos pacientes, estas eram múltiplas (Figura 4). Vale

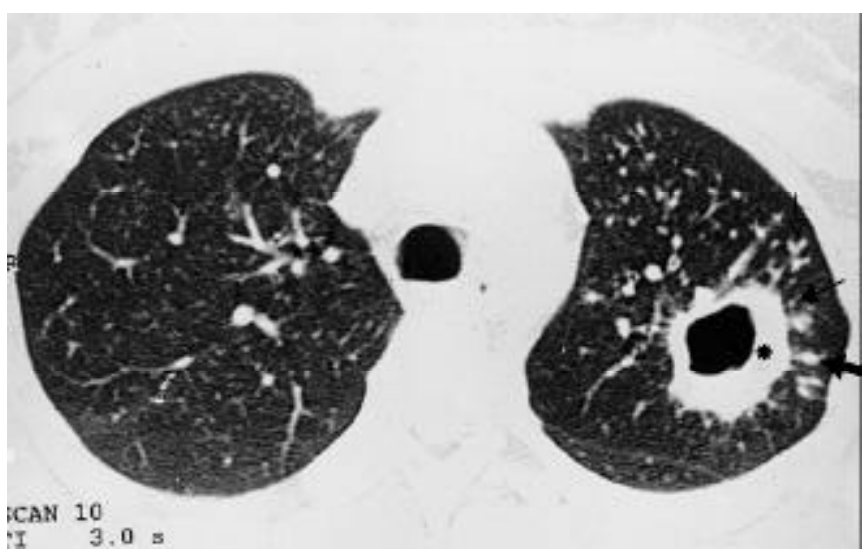

Figura 3 - TCAR. Cavidade de paredes espessas e contornos externos irregulares (asterisco) no lobo superior esquerdo, associada a nódulos do espaço aéreo (seta grossa), opacidades com aspecto de árvore em brotamento (seta vazada) e nódulos centrolobulares (seta fina).

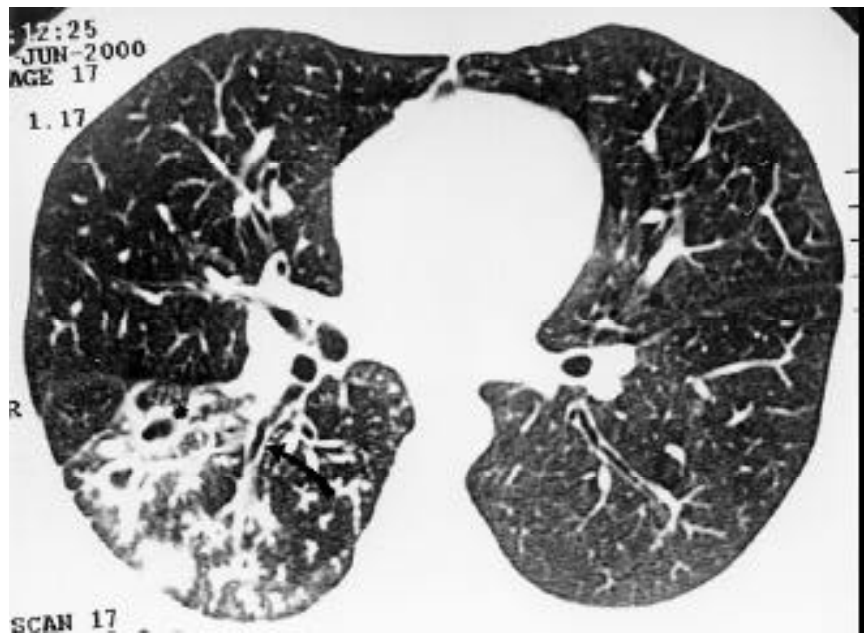

Figura 5 - TCAR. Pequenas cavidades de paredes espessas e contornos irregulares (asterisco), associadas a nódulos do espaço aéreo, opacidades centrolobulares ramificadas e brônquio de paredes espessadas (seta curva) no segmento superior do lobo inferior direito.

destacar a constante associação entre consolidação e nódulos do espaço aéreo (95\%). Com freqüência, os nódulos do espaço aéreo se apresentavam confluentes, formando condensações lobulares.

$\mathrm{O}$ espessamento de paredes brônquicas foi encontrado em 23 pacientes (55\%). Em todos os pacientes com espessamento de paredes brônquicas foram também encontrados nódulos do espaço aéreo (Figura 5).

Dos 42 pacientes, nove (21\%) apresentaram opacidades em vidro fosco. Em seis dos casos, essas opacidades foram encontradas em torno de lesões nodulares. Três 
pacientes apresentaram esse padrão de forma esparsa pelo parênquima pulmonar.

O espessamento do interstício intra e/ou interlobular foi observado em quatro pacientes $(9 \%)$; nesses casos, o quadro radiológico foi bastante exuberante, com a presença de cavidades, nódulos centrolobulares e do espaço aéreo, aspecto de árvore em brotamento e espessamento das paredes brônquicas.

Outros achados encontrados com menor freqüência foram nódulos maiores do que $1 \mathrm{~cm}$, bandas parenquimatosas, enfisema centrolobular, perfusão em mosaico $e$ imagem nodular com densidade de partes moles intrabrônquica.

O Quadro 3 mostra os principais sinais tomográficos de atividade da tuberculose pulmonar observados em cada paciente e seus percentuais.

\section{DISCUSSÃO}

A TCAR, por ser um método extremamente eficaz na avaliação do lóbulo pulmonar secundário, permite melhor caracterização dos processos patológicos pulmonares. Em relação à tuberculose, vem-se mostrando muito útil em situações nas quais a radiografia de tórax não contribui para o diagnóstico de doença em atividade, seja pela presença de alterações parenquimatosas mínimas, seja por não permitir distinguir lesões antigas fibróticas das lesões características de disseminação broncogêni$\mathrm{ca}^{(4,5,13,16)}$.

Na nossa casuística, 32 pacientes $(76 \%)$ apresentaram baciloscopia positiva e 10 (24\%), baciloscopia negativa, fato esse que corrobora os dados da literatura mundial ${ }^{(4-}$ ${ }^{6,8)}$, em que, nas diversas casuísticas, o percentual de baciloscopias negativas em pacientes com doença em atividade variou de 21 a $47 \%$. Nos trabalhos que envolveram pacientes com tuberculose miliar, houve freqüência maior de baciloscopia negativa, que variou de 36 a $66 \%$ dos casos $^{(6,8)}$.

\begin{tabular}{|lcr|}
\hline \multicolumn{3}{|c|}{ QUADRO 3 } \\
\hline \multicolumn{3}{|c|}{ Relação de achados na TCAR } \\
\hline Achados tomográficos & $N^{\circ}$ de casos & (n = 42) \\
\hline N ódulos do espaço aéreo & 35 & 83 \\
N ódulos centrolobulares & 31 & 74 \\
Cavitação & 28 & 67 \\
"Árvore em brotamento" & 28 & 67 \\
Espessamento das paredes brônquicas & 23 & 55 \\
Consolidação & 20 & 48 \\
O pacidade em vidro fosco & 9 & 21 \\
Espessamento do interstício inter/intralobular & 4 & 9 \\
\hline
\end{tabular}

$\mathrm{O}$ acometimento de múltiplos lobos pulmonares predominou, ocorrendo em 29 pacientes (69\%). Esse achado é habitualmente relatado na forma pós-primária, mas também pode ocorrer na forma primária( ${ }^{(7,13-15)}$. No trabalho de Woodring et al. ${ }^{(7)}$, o envolvimento de dois ou mais lobos ocorreu em $87,5 \%$ dos casos de tuberculose pósprimária e em $23,7 \%$ na forma primária.

Os segmentos apical e posterior do lobo superior direito, apicoposterior do lobo superior esquerdo e superiores dos lobos inferiores são os mais envolvidos. Segundo a literatura mundial, esses achados são freqüentes na tuberculose pós-primáriaa ${ }^{(7,14,15)}$.

Em relação à avaliação da TCAR dos 42 pacientes, observou-se predomínio dos nódulos do espaço aéreo (83\%), dos nódulos centrolobulares (74\%), do aspecto de árvore em brotamento (67\%) e das cavitações (67\%), em relação aos outros achados, como o espessamento das paredes brônquicas (55\%), consolidações (48\%), opacidade em vidro fosco $(21 \%)$ e espessamento de septos inter e intralobulares (9\%). Esses dados encontram-se em concordância com os apresentados pela literatura ${ }^{(4,5,13)}$.

Os sinais de disseminação broncogênica foram os nódulos do espaço aéreo, os nódulos centrolobulares e o aspecto de árvore em brotamento, corroborando os trabalhos de Im et al. ${ }^{(5)}$ e Hatipoglu et al. ${ }^{(4)}$, que observaram esses achados em $68-69 \%, 91-97 \%$ e $71-72 \%$ dos casos, respectivamente. No trabalho de Im et al. ${ }^{(5)}$, além das alterações já descritas, houve destaque para o espessamento de paredes brônquicas na disseminação broncogênica, que apresentou uma freqüência de $79 \%$.

Neste trabalho observamos freqüência um pouco maior dos nódulos do espaço aéreo (83\%) e menor dos nódulos centrolobulares $(74 \%)$ e do aspecto de árvore em brotamento (67\%), quando comparamos com os resultados dos trabalhos consultados e já citados anteriormente ${ }^{(4,5)}$. Os estudos de Itoh et al. ${ }^{(16)}$ e Im et al. ${ }^{(5)}$ mostraram que os nódulos do espaço aéreo são nódulos centrolobulares que crescem e coalescem, e que após a instituição de antibioticoterapia se tornam menores e com limites definidos. Além disso, nas tomografias seqüenciais realizadas por Im et al. ${ }^{(5)}$, a resolução da consolidação pulmonar iniciava-se pela periferia, com aparecimento de nódulos do espaço aéreo e, posteriormente, nódulos centrolobulares. Portanto, a freqüência elevada dos nódulos do espaço aéreo observada neste trabalho pode estar relacionada ao tempo de doença em atividade e de antibioticoterapia instituída.

Quarenta e um pacientes (98\%) apresentavam algum tipo de opacidade centrolobular, característico da disseminação broncogênica, dado este semelhante aos relatados em vários estudos, que variam de 68 a 97\% dos ca$\operatorname{sos}^{(4,5)}$. 
A cavitação foi um achado comum, ocorrendo em $67 \%$ dos pacientes, sendo múltiplas em $53 \%$ dos casos e de paredes espessas e bordas irregulares em $86 \%$, como habitualmente encontrado na literatura ${ }^{(4,5,7,13,14)}$. Poey et al. ${ }^{(13)}$ destacaram, em um estudo com 27 pacientes, que todas as cavidades $(100 \%)$ apresentavam paredes espessas e que estas tornavam-se mais finas com o tratamento.

A presença de nível líquido no interior das cavidades ocorreu em 9\% dos casos, sendo esta freqüência menor do que a encontrada na literatura. Woodring et al. ${ }^{(7)}$ relataram que $20 \%$ das cavidades apresentavam nível líquido $e$ Poey et al. ${ }^{(13)}$ observaram freqüência ainda maior, chegando a ocorrer em $25 \%$ dos casos.

A consolidação do parênquima pulmonar foi encontrada em $48 \%$ dos pacientes; na metade deles o acometimento era múltiplo, dados estes semelhantes aos habitualmente relatados ${ }^{(4,5)}$. Choi et al. ${ }^{\left({ }^{9}\right)}$ verificaram freqüência maior, já que $73 \%$ dos pacientes por eles estudados apresentavam consolidação. Essa diferença pode ser explicada em virtude de seu estudo ter sido realizado com pacientes graves, cursando com quadro de insuficiência respiratória aguda, conseqüentemente com mais achados clínicos e radiológicos.

É importante ressaltar a associação, neste trabalho, de nódulos do espaço aéreo com áreas de consolidação do parênquima pulmonar. Webb et al. ${ }^{(17)}$ já haviam destacado que esses nódulos representam áreas peribronquiolares de consolidação do espaço aéreo e que sempre aparecem na periferia de consolidações confluentes.

$\mathrm{O}$ espessamento de paredes brônquicas, normalmente observado em associação com outros sinais de disseminação broncogênica, ocorreu em $55 \%$ dos casos, freqüência esta semelhante à relatada pela literatura, que é de 44 a $79 \%{ }^{(4,5)}$.

A opacidade em vidro fosco foi encontrada em nove (21\%) dos 42 pacientes estudados; em seis deles era perinodular e em três, esparsa. Essa freqüência é menor do que a relatada na literatura, que é de $35-38 \%{ }^{(4,12)}$. Poey et al. ${ }^{(13)}$, que destacaram a importância da opacidade em vidro fosco, não só na avaliação da atividade da doença como na avaliação da eficiência do tratamento, observaram freqüência bem maior do achado de opacidade em vidro fosco nos seus pacientes, que foi de $95 \%$, desaparecendo em $75 \%$ dos casos após dois meses de terapia antituberculosa. Portanto, a baixa freqüência da opacidade em vidro fosco observada no nosso trabalho poderia ser explicada pelo tempo de antibioticoterapia que os pacientes apresentavam quando realizaram a TCAR.

O espessamento do interstício pulmonar, traduzido pelo espessamento dos septos inter e intralobulares, foi observado em $9 \%$ dos casos, freqüência esta menor do que os trabalhos de Im et al. ${ }^{(5)}$, Hatipoglu et al. ${ }^{(4)}$ e Poey et al. ${ }^{(13)}$, que encontraram freqüências variando de 34 a $47 \%$. Segundo Im et al. ${ }^{(5)}$, o espessamento dos septos inter $e$ intralobulares pode ser explicado pela presença de material caseoso nos septos e/ou pela redução da drenagem linfática, causada pela presença de linfonodomegalias centrais, que desaparecem com a antibioticoterapia. Esse estudo destacou o completo desaparecimento desse achado após três meses de tratamento específico. Mais uma vez, o maior tempo de antibioticoterapia dos pacientes estudados pode ter sido responsável pela menor freqüência desse achado no nosso trabalho.

Os casos de nódulos maiores do que $1 \mathrm{~cm}$ e de lesão com densidade de partes moles endobrônquica, apesar de não ter sido possível a confirmação histopatológica, podem representar a presença de tuberculomas e de lesão tuberculosa endobrônquica, respectivamente.

Por fim, nosso trabalho demonstrou que a TCAR pode ser de extrema importância na avaliação da presença de opacidades centrolobulares, que são os sinais mais precoces da disseminação broncogênica, e que podem não ser observadas nas radiografias de tórax. Isso pode ser e foi muito útil naqueles pacientes com forte suspeita clínica de tuberculose pulmonar e que apresentam baciloscopia negativa, permitindo o início da antibioticoterapia precoce.

É importante salientar que nenhum dos achados tomográficos é absoluto, devendo sempre ser interpretados pelo clínico em conjunto com os dados clínicos associados a investigação bacteriológica adequada.

\section{AgRAdECIMENTOS}

Aos médicos do Programa de Controle de Tuberculose Hospitalar ( $\mathrm{PCTH}$ ) do Hospital Universitário Clementino Fraga Filho (HUCFF), sob a coordenação do Prof. Afrânio L. Kritski, em especial à Dra. Cristiane Salles, pelo apoio e generosa contribuição dos casos.

\section{REFERÊNCIAS}

1. Kritski AL, Souza GRM, Gontijo Filho PP. A tuberculose como um problema de infecção hospitalar no Brasil. J Pneumol 1988;14:13-8.

2. Kritski AL, Souza GRM, Conde MB, et al. Manual de normas do controle da tuberculose, $1^{\text {a }}$ ed. Rio de Janeiro, 1999.

3. Brasil. Ministério da Saúde. Plano nacional de controle da tuberculose. Brasília, 2001. [Cited 2001 fev 17] Available from: http://www.saude. gov.br/programas/tuberculose.

4. Hatipoglu ON, Osma E, Manisali M, Ucan ES, Balci P, Akkoclu A, et al. High resolution computed tomographic findings in pulmonary tuberculosis. Thorax 1996;51:397-402.

5. Im JG, Itoh H, Shim YS, et al. Pulmonary tuberculosis: CT findings Early active disease and sequential change with antituberculous therapy. Radiology 1993;186:653-60.

6. McGuinness G, Naidich DP, Jagirdar J, Leitman B, McCauley D. High resolution $\mathrm{CT}$ findings in miliary lung disease. J Comput Assist Tomogr 1992;16:384-90. 
7. Woodring JH, Vandiviere HM, Fried AM, Dillon MI, Willians TD, Melven JG. Update: the radiographic features of pulmonary tuberculosis. AJR 1986;146:497-506

8. Oh YW, Kim YH, Lee NJ, Kim JH, Chung KB, Suh WH, Yoo SW. High resolution CT appearance of miliary tuberculosis. J Comput Assist Tomogr 1994;18:862-6.

9. Choi D, Lee KS, Suh GH, Kim TS, Kwon OJ, Rhee CH, Han J. Pulmonary tuberculosis presenting as acute respiratory failure: radiologic findings. J Comput Assist Tomogr 1999;23:107-13.

10. Lee KS, Kim TS, Han J. Diffuse micronodular lung disease: HRCT and pathologic findings. J Comput Assist Tomogr 1999;23:99-106.

11. Hong SH, IM JG, Lee JS, Song JW, Lee HL, Yeon KM. HRCT findings of miliary tuberculosis. J Comput Assist Tomogr 1998;22:2204.
12. Lee KS, Hwang JW, Chung MP, Kim H, Kwon OJ. Utility of CT in evaluation of pulmonary tuberculosis in patients without AIDS. Chest 1996;110:977-84.

13. Poey C, Verhaegen F, Giron J, Lavayssiere J, Fajadet P, Dupare B. High resolution chest $\mathrm{CT}$ in tuberculosis: evolutive patterns and signs of activity. J Comput Assist Tomogr 1997;21:601-7.

14. Leung AN. Pulmonary tuberculosis: the essentials. Radiology 1999; 210:307-22.

15. Lee KS, Im JG. CT in adults with tuberculosis of the chest: characteristic finding and role in management. Am J Roentgenol 1995;164: 1361-7.

16. Itoh $\mathrm{H}$, Tokunaga $\mathrm{S}$, Asamoto $\mathrm{H}$. Radiologic-pathologic correlation of small lung nodules with special reference to peribronchial nodules. Am J Roentegenol 1978;130:223-31.

17. Webb WR, Müller NL, Naidich DP. High-resolution CT of the lung. $3^{\text {rd }}$ ed. Philadelphia: Lippincott-Raven, 2000. 